\title{
Familia y escuela: estudio de la discapacidad desde la inclusión y la equidad
}

\section{Family and school: study of disability from inclusion and equity}

Jenny Andrea Quiroz Villacís

Universidad de Especialidades Espíritu Santo, Ecuador

Autor para correspondencia: jaquiroz@uees.edu.ec

Fecha de recepción: 13 de abril de 2018 Fecha de aceptación: 15 noviembre del 2018

\begin{abstract}
Resumen
Lograr un mayor acercamiento de la familia a la escuela. La comunidad educativa no puede concebirse sin la incorporación activa de los padres de familia. La participación de los padres es sin duda un derecho pero también un deber. Esto origina la investigación y análisis de este discurso para describir los elementos que allí intervienen, es una investigación de enfoque cualitativo, método Hermenéutico. Los resultados de la investigación arrojaron que el rol de la familia es determinante en el éxito escolar, y en la vida misma del niño con discapacidad, toda vez que destaca que un pilar fundamental para la equidad, la comunicación entre la escuela y la familia. De acuerdo con los hallazgos, se destacó la importancia de una visión educativa que trascienda de lo estrictamente educacional y se convierta en una herramienta fundamental para la transformación de vida del niño con discapacidad, puntualizando los alcances y el valor como epicentro para la formación de una nueva sociedad la integración entre la escuela y la familia que proyecte una verdadera inclusión con equidad.
\end{abstract}

Palabras claves: familia; escuela; discapacidad; inclusión; equidad

\begin{abstract}
Achieve a greater approach of the family to school. The educational community cannot be conceived without the active incorporation of parents. The participation of parents is undoubtedly a right but also a duty. This originates the investigation and analysis of this discourse to describe the elements that intervene there; it is a research of qualitative approach, Hermeneutical method. The results of the investigation showed that the role of the family is determinant in the school success, and in the life itself of the child with disability, since it emphasizes that a fundamental pillar for equity, communication between the school and the family. According to the findings, the importance of an educational vision that transcends the strictly educational and becomes a fundamental tool for the transformation of the life of children with disabilities, highlighting the scope and value as an epicenter for the formation of a new society the integration between the school and the family that projects a true inclusion with equity.
\end{abstract}

Key words: family; school; disability; inclusion; equity 


\section{Introducción}

La educación desde una perspectiva mundial, es concebida como un derecho universal, y un continuo humano. Por tal motivo, la familia y la escuela, son consideradas desde siempre, los pilares fundamentales para la formación integral del individuo. Al respecto, Delgado (2009), señala que la educación es un proceso que va acompañado de múltiples elementos, y en consecuencia es compleja y variada, por lo que en palabras del autor, va más allá de lo intelectual, dado que abarca manifestaciones espirituales, emocionales lo que viene a configurarla como la perfección de todas las manifestaciones de la naturaleza humana.

Dentro de este orden de ideas, la educación se concibe no como un solo proceso de enseñanza, sino también como un proceso de aprendizaje y formación de la persona, como un acto ineludible en todas las áreas de la vida y del conocimiento humano. A tal efecto, Blanco (2009), considera que dentro de las finalidades de la educación está "preparar a las personas para que participen en las distintas actividades de la vida humana y para que puedan tomar decisiones sobre aquellos aspectos que afectan sus vidas y de sus comunidades"(s/p) y, a este particular, la familia se simboliza como un factor importante para crear las bases del futuro de las diferentes sociedades del mundo entero.

En este marco de ideas, es importante la participación e involucración de los padres y representantes en proceso educativo de los niños, ya que es desde el hogar que se inicia la atención y en consecuencia el éxito del futuro individuo en la sociedad.

Atendiendo a las ideas antes señaladas, la educación inclusiva se inicia desde los primeros años de vida del niño, y desde el hogar. Entendida ésta de acuerdo a la Organización de las Naciones Unidas para la Educación, la Ciencia y la Cultura (Unesco 2008), como un principio rector general para reforzar el aprendizaje a lo largo de toda la vida, y con acceso a las oportunidades de aprendizaje en condiciones de igualdad para todos los niveles de la sociedad. A tal efecto, desde la familia se debe considerar que a través de la participación que se genera en su seno, se propicia las condiciones de una educación inclusiva, y en consecuencia conlleva a la atención a niños con discapacidad. Al respecto, la Organización de Naciones (ONU, 2006), expresa que, hoy no hay ninguna duda que los alumnos con discapacidad tienen reconocido su derecho a participar como cualquier otro en la educación general tal como se recoge en la Convención sobre los derechos de las personas con discapacidad. De acuerdo a las ideas antes expuestas, la familia entonces juega un rol protagónico en la inserción de los niños con discapacidad no solo en el ámbito escolar sino también en el devenir de la cotidianidad.

De manera tal que, según la Revista Iberoamericana sobre Calidad, Eficacia y Cambio en Educación (2013), la familia es el lugar de la primera educación. Es donde el niño nace de un proyecto de la responsabilidad parental que le procura cuidado en vistas a su futuro, su construcción, su preparación como persona del mejor modo posible. Por lo que, también es considerada un lugar de respeto de las libertades. En este orden de ideas, los padres a través de su misión educativa, junto a la escuela ayudan a fortalecer la autosuficiencia y promover la autonomía del niño. Por tal motivo, la educación inclusiva de los niños con discapacidad tiene su origen en la familia, y se fortalece en la escuela así como en el desempeño de sus miembros, y de esto depende en gran medida la aceptación no solo del entorno sino también del niño con sus 
propias características. Es importante entonces el rol de la familia y de la escuela en la inclusión de los niños con discapacidad ya que la aceptación conlleva al desarrollo integral del niño como acto educativo.

De allí la importancia del papel protagónico que debe asumir la familia, en consonancia con la escuela con el fin de favorecer las condiciones óptimas para la inclusión de los niños con discapacidad con el propósito de éstos puedan participar en igualdad de oportunidades, siendo necesario eliminar todas aquellas barreras que lo impidan

En este orden de ideas, Bayot, Rincón y Hernández (2002) entienden que los distintos ámbitos atienden la diversidad si parten de las diferencias y las aprovechan para el crecimiento personal y colectivo de los individuos. Dentro de este marco, las instituciones educativas y la familia deben ser conscientes de que el proceso de construcción personal depende de las características individuales (de su diversidad), pero sobre todo de los apoyos y de las ayudas que se proporcionen.

Sin embargo, la realidad en este sentido, discrepa de la teoría. Investigaciones al respecto han centrado su foco de atención en indagar el papel de la familia y la escuela en el proceso de inclusión de niños con discapacidad. Prueba de ello, lo constituye el estudio desarrollado por Romero quien en el 2015 realizó una experiencia investigativa para la Universidad Complutense de Madrid que tituló Inclusión, Ética, Escuela y Familia. . El propósito principal del estudio conocer la necesidad de dar respuesta a las tendencias actuales en el área investigativa en torno a desarrollar proyectos con mayor sentido de responsabilidad, en la que se respeten a todos los seres vivos con discapacidad, y en la que se beneficien todos los involucrados, a partir de la integración escuela y familia teniendo como vía fundamental la Ética. De acuerdo a los resultados de la investigación la familia presenta cierta resistencia para aceptar los hijos con discapacidad, y más aún atender las condiciones para la inclusión, por lo que se refleja una actitud de cierto desgano y en algunos casos dejar a la escuela toda responsabilidad de formación de los niños.

En atención a los planteamientos descritos, desde una visión cualitativa y a través de un acercamiento hermenéutico desde un contexto natural se realiza la presente investigación la cual pretende estudiar el rol de la familia y la escuela en la inclusión y equidad de niños con discapacidad.

A partir de las apreciaciones anteriores, se pretende con este estudio dar respuesta a las siguientes interrogantes;

¿Cómo se percibe el proceso de equidad de estudiantes de educación Básica con discapacidad en las instituciones educativas de Guayaquil?

\section{Objetivos de la Investigación}

- Profundizar los supuestos teóricos referenciales de la inclusión educativa

- Conocer el proceso de inclusión de estudiantes de educación Básica con discapacidad en las instituciones educativas de Guayaquil. 
- Interpretar la importancia del rol de la familia y la escuela en la inclusión y equidad educativa en estudiantes de educación Básica en Guayaquil.

\section{Aportaciones del estudio}

La discapacidad puede repercutir en el ámbito académico, en el campo de las relaciones sociales y en el contexto de la vida cotidiana. Esa influencia puede estar asociada a algunos de los siguientes aspectos:

a) actitudes familiares y sociales, referidas principalmente a la relación de la familia, grado de aceptación, calidad de las relaciones y apoyo de los organismos.

b) características personales del sujeto con discapacidad.

Dentro de esta perspectiva, la presente investigación tiene relevancia social por cuanto la educación, y en sí la inclusión es un derecho de todo individuo con discapacidad, y en este sentido, los niños como futuro de la sociedad han de estar en un contexto y oportunidades de equidad e inclusión, y a través de este estudio, se pretende hacer una reflexión acerca de cómo se está desarrollando estos procesos de inclusión y equidad en ámbito natural.

\section{Referentes Teóricos}

\section{La Discapacidad}

La concepción de la discapacidad se ha construido a través de diversos enfoques y ha presentado una evolución heterogénea en las sociedades y organizaciones mundiales, a través de diferentes perspectivas. Existen múltiples modalidades de conocimiento científico para aproximarse a la discapacidad. Una de las formas de aproximación al conocimiento de la discapacidad es a través de la evolución cronológica, observando según los momentos históricos, epistemológicos y filosóficos las respuestas que la sociedad ha ofrecido a las personas con discapacidad. Las diversas reflexiones sobre la diferencia humana nos conducen a descubrir una serie de estructuras conceptuales a través de la historia.

En el panorama general de las diferentes culturas, las personas con discapacidad han sido representadas con una diversidad de significados, como destaca Aguado (1995:26). Desde la antigüedad hasta nuestros días, han existido grandes contradicciones en el tratamiento otorgado a las Personas con Discapacidad (PcD), consideradas por un lado como personas especiales y también como personas desafortunadas. Ambas conceptualizaciones: discriminación e inclusión han derivado en una dualidad contradictoria constante en la forma del trato social.

En la opinión de Pisonero (2007), sobre la conceptualización de la discapacidad y formas de trato humano, aparece como una constante histórica durante largos periodos, la marginación social; en relación al tema Burgdorf (1980:51), indica: "la historia de los procedimientos formales de la discapacidad para enfrentarse a las personas minusválidas pueden sintetizarse en dos palabras: segregación y desigualdad". 
La conceptualización de la discapacidad, continuando con los aportes de Pisonero (ob.cit) se ha modificado de acuerdo a la época y el lugar en el que se desarrolla, la perspectiva que prevalece en ese momento de la historia siendo establecida por el grupo de expertos encargados de establecer los criterios sobre las percepciones y actitudes hacia la discapacidad, las cuales están sujetas a interpretaciones culturales que dependen de valores, de condiciones económicas y políticas, así como del avance científico de la época.

Durante un largo período histórico, del Siglo XVI al XIX, el paradigma dominante incluyó a la discapacidad en el marco de la salud, concibiéndola como una enfermedad. Bajo esta referencia conceptual, la discapacidad fue caracterizada como deficiencia; fue vista como una desviación dentro del modelo de normalidad. A principios del Siglo XX, aún bajo este enfoque, la discapacidad fue cualificada con criterios de exclusión, por lo que las Personas con Discapacidad fueron clasificadas como individuos que debían ser rechazados por el grupo social.

Las nuevas concepciones de la discapacidad se desarrollaron a partir del amplio cuestionamiento de las condiciones y las relaciones psico-sociales que se producen en el contexto de la diferencia humana, permitiendo a estas personas con necesidades especiales ser partícipes activos en la sociedad (Cabra de Luna, 2004; Cabra de Luna, Bariffi y Palacios, 2007). Posteriormente a la Segunda Guerra Mundial, existieron diferentes condiciones sociales, económicas y políticas que influyeron en la atención de las Personas con Discapacidad. Pasando del problema de la minusvalía a un paradigma de hombre útil o inútil, apto o no apto con relación al desarrollo industrial de la sociedad, a la producción y al consumo.

La Organización de las Naciones Unidas (ONU) después de la segunda guerra mundial, con un amplio trabajo de los estados miembro, centra su interés en temas de ética reafirmando las concepciones del ser humano, de la libertad y de la justicia. Los tratados internacionales de esta organización establecieron la concepción de desarrollo humano solidario, enfatizando que el total de las personas en el mundo deben tener posibilidades materiales para satisfacer sus necesidades de vida. Entre los acuerdos internacionales fundamentales se encuentran: la Carta de las Naciones Unidas (ONU, 1945), y la Declaración Universal de los Derechos Humanos (ONU, 1948). A partir del periodo posterior a la segunda guerra mundial el trabajo internacional se ha caracterizado por evitar las desigualdades, la marginación, la segregación y la exclusión.

Durante la segunda parte del Siglo XX se consideró que las causas que originan la discapacidad no son ni religiosas, ni científicas, sino que son en gran medida, psicológicas y sociales. Desde esta ideología se insistió en que las Personas con discapacidad pueden aportar a la sociedad en igual medida que el resto de las personas sin discapacidad siempre desde la valoración y el respeto de la diferencia.

Estos nuevos constructos de pensamiento generaron las bases para el desarrollo del bienestar de las Personas con discapacidad. Bajo esta nueva concepción, en la ONU se establecieron diferentes acuerdos internacionales en los que se afirma que todas las con necesidades educativas especiales, deben poder ejercer sus derechos civiles, políticos, sociales y culturales en igualdad de condiciones que el resto de la población: Declaración de los Derechos de las Personas con Retraso Mental (1971), la Declaración de los Derechos de las Personas con Discapacidad (1975), Programa de Acción Mundial para las personas con discapacidad (1982), las Normas Uniformes para la igualdad de oportunidades de las personas con discapacidad 
(1993), Convención de los derechos humanos de las personas con discapacidad (2006). Con estos fundamentos, se defendió el derecho de que todas las personas han de acceder, en igualdad de condiciones y oportunidades, a la educación, a la formación profesional, al trabajo y a la vida plena en la sociedad. La concepción de la Salud orientó los trabajos de la Organización Mundial de la Salud durante la mayor parte del Siglo XX, pero fue hasta la década de los setenta, cuando este organismo inició los trabajos para delimitar la concepción que hasta esas fechas prevalecía sobre la discapacidad.

Ahora bien, el modelo conceptual que la Clasificación Internacional del Funcionamiento de la Discapacidad y la Salud (CIF) establece para entender la discapacidad y su funcionamiento, es proporcionar una visión multidimensional de la salud, desde un enfoque Bio-Psico-Social. La CIF está basada en la integración del modelo médico y el modelo social. La CIF intenta conseguir una síntesis y, así, proporcionar una visión coherente de las diferentes dimensiones de la salud desde una perspectiva biológica, individual y social.

Bajo este modelo, la discapacidad se conceptualiza como un problema personal y social, que requiere no sólo atención médica y rehabilitadora, sino también apoyo para la integración social, a la que ha de darse respuesta mediante tratamientos individuales a través de la acción social. De esta manera, las formas de atención para las personas con discapacidad involucran programas de acción tanto en cambios personales, como de cambios en el entorno.

La Organización Mundial de la Salud (p.175), en relación a la Clasificación Internacional del Funcionamiento de la Discapacidad y de la Salud sustenta:

El punto de vista que hasta ahora se seguía para considerar y clasificar las dimensiones relacionadas con la salud y la discapacidad se ha visto modificada y actualizada gracias a la elaboración por parte de la Organización Mundial de la Salud (OMS) de la Clasificación Internacional del Funcionamiento, de la Discapacidad y de la Salud (CIF). La CIF, nuevo miembro de la familia de clasificaciones internacionales de la OMS, describe cómo vi- ven las personas su estado de salud. Es una clasificación de dominios de la salud y de los aspectos relacionados con la salud que describen las funciones y estructuras del organismo, las actividades y la participación. Los dominios se clasifican desde una perspectiva corporal, individual y social. Como el funcionamiento y la discapacidad de una persona se enmarcan en un determinado contexto, la CIF también incluye una lista de factores ambientales.

Esta clasificación tuvo la importancia de ayudar a obtener una visión global, a través de la cual es posible comprender y explicar la vivencia de la discapacidad, considerando el concepto de autonomía como un núcleo central y la acción de la inclusión e integración como objetivo a alcanzar.

\section{Equidad Educativa}

La ONU ha promovido una serie de encuentros internacionales en los que se han planteado problemáticas específicas de las Personas con discapacidad en la educación superior. Los temas recurrentes se constituyen desde el derecho básico a la educación, los principios de igualdad de oportunidades en el acceso a la educación superior y el tema de la discriminación que cultural y educativamente ha excluido a las personas con necesidades educativas especiales. 
La UNESCO, ha organizado diversos encuentros internacionales desarrollando los temas que incluyen el derecho básico a la educación, y los acuerdos sobre la equidad en el acceso a la Educación, con el claro objetivo de establecer cambios que favorezcan la igualdad de oportunidades a los estudiantes con discapacidad. A tsl efecto, el derecho a la educación significa el derecho a aprender a lo largo de la vida y está fundado en los principios de obligatoriedad, gratuidad, y en el derecho a la no discriminación.

El principio de la equidad en el acceso a la educación, permite a los niños con necesidades educativas especiales ejercer sus derechos de ingreso, permanencia y egreso a la educación independientemente de las condiciones de discapacidad y reservando la posibilidad de realizar su vida de acuerdo a sus posibilidades y capacidades respetando la individualidad.

Desde un enfoque de derechos humanos, no basta con la igualdad de acceso, sino que es preciso avanzar hacia la igualdad de condiciones para que todos los estudiantes desarrollen al máximo sus potencialidades y alcancen los mejores resultados; es decir, poder ejercer el derecho a aprender en igualdad de condiciones en los espacios educativos.

Es difícil separar calidad de equidad, si se considera que la equidad no es sólo igualdad de acceso, sino también de derechos a recibir una educación de calidad, y un criterio importante para definir una educación de calidad es precisamente que ésta sea capaz de dar respuesta a la diversidad.

Los niños con necesidades educativas especiales, haciendo valer su derecho a la educación, deben tener la posibilidad de ingresar a una escuela, en donde reciban educación de calidad, accediendo efectivamente a la currícula general, permitiéndoles aprender y desarrollar las competencias que les darán la oportunidad de participar en el desarrollo colectivo, alcanzar un mejor crecimiento personal, llegar a ser auto determinante con la capacidad de dirigir su propia vida, disponiendo de una posibilidad de avanzar en el saber e ingresando a los diferentes niveles de educación y preparándose para ser personas activas en el ámbito de participación económica con autonomía.

\section{Inclusión Educativa de los niños con Discapacidad}

La inclusión de los niños con discapacidad es de gran importancia para responder a sus necesidades educativas para desarrollar sus capacidades y potencialidades en los Centros de Educación. La inclusión de estos niños integrados a centros de educación regular, pretende que los mismos sean aceptados, valorados y que se sientan comprendidos en un ambiente donde se potencialicen sus destrezas y habilidades. La escolarización supone para el niño la separación de la madre y de la seguridad que le proporciona. Para la madre y el padre también supone la separación y el tener que confiar a otros el cuidado y la educación del niño. «El proceso de separación es imprescindible para que el niño se haga persona, pero el ritmo debe ser respetuoso con su proceso de maduración» (Lucerga y Gaston, 2004)

Las necesidades educativas de los niños con discapacidad son muy diversas. Es por esta razón que es necesario un currículo que sea flexible, abierto a la posibilidad de realizar cambios en el mismo y que se adapte a las diferentes necesidades, características, potencialidades y 
particularidades individuales de cada uno de los niños que presenta discapacidad. En consecuencia, la educación del alumnado con discapacidad debe ser la misma que el resto del grupo pero adaptando los materiales y técnicas a sus capacidades específicas.

\section{Metodología}

Desde el punto de vista epistemológico esta investigación se desarrolla a través del enfoque cualitativo. Esto debido a que en la actualidad, el matiz humano cobra relevancia en estudios referidos a las ciencias sociales. Al respecto, Martínez (2001) al hacer referencia a las ciencias humanas, plantea que “...estas están rodeadas de una realidad muy compleja para tratar de explicarlo de manera analítica-mecanicista" (P.76). De acuerdo a esto, la realidad es tan complicada, que es conveniente conocer la misma bajo una visión holística, lo que permitiría ver el fenómeno de una manera total, integradora, en constante interacción, de modo que la tendencia cuantitativa limitaría, este conocimiento, pues al estudiar la realidad, tiende a separar y aislar todos sus aspectos.

\section{Método}

A manera de dar respuesta a los objetivos de este estudio, se asume la hermenéutica como el método idóneo para conocer el evento de estudio. A tal efecto, Dilthey (citado en Martínez, 2004), señala que el método hermenéutico;

...tendría como misión descubrir los significados de las cosas, interpretan mejor posible las palabras, los escritos, los textos, los gestos y, en general, el comportamiento humano, así como cualquier acto u obra suya, pero conservando su singularidad en el contexto de que forma parte. (P. 102).

En tal sentido, en esta investigación se logró captar el significado de las palabras y hacer una interpretación lo más rigurosa posible de las mismas, de las acciones y gestos de los sujetos estudiados, procurando entender su singularidad desde el contexto al cual pertenecen.

\section{Informantes de la Investigación}

En cuanto a los informantes, los sujetos seleccionados para la investigación siguieron las características de sujeto-tipo, que para Hernández, Fernández y Baptista (2003) quien expone que estos sujetos son "...los que se utilizan en las investigaciones cualitativas, donde el objetivo es la riqueza, profundidad y calidad de la información, no la cantidad ni estandarización". (P.328).

En tal sentido, para efectos de este estudio los informantes clave estuvieron conformados por dos docentes y un representante de la institución escenario del estudio.

\section{Técnicas e Instrumentos de Información}

En respuesta a los objetivos de esta investigación se hizo uso de la técnica de la observación participante y de la entrevista. En este orden de ideas, Taylor y Bogdan (1992) 
expresan la entrevista, como reiterados encuentros cara a cara entre el investigador y los informantes. En este sentido Martínez (2004) señala que la entrevista;

Es un instrumento técnico que tiene gran sintonía epistemológica con el enfoque, este consistirá en la recogida de información a través de un proceso de comunicación en el transcurso de la cual el entrevistado proporcionará la información directamente al entrevistador. (P.8).

La aplicación de estas técnicas, propicia la acción dialógica al recopilar la información de manera directa, y con los elementos necesarios para su interpretación. De igual manera, se hizo uso del grabador y cuaderno de campo. En relación a la observación participante, Hurtado y Toro (2001), manifiestan que la observación participante, implica que el investigador se introduzca con el objeto de estudio, lo que representa que este se involucre en las acciones del grupo observado y su entorno.

\section{Técnicas de Interpretación de la Información}

Dado que la investigación es de naturaleza cualitativa, la información suministrada se interpretó mediante la categorización, la estructuración y la triangulación.

\section{Análisis de los Resultados}

Aplicada la entrevista a los sujetos de la investigación se procedió a categorizar la información con el fin de extraer las categorías y subcategorías. Luego se procedió a estructurar los hallazgos. Posteriormente, con el fin de dar fiabilidad a la información se hizo uso de la triangulación.

\section{Categorización de la Información}

\begin{tabular}{|c|c|c|}
\hline Informante & Sub Categoría & Categoría \\
\hline \multirow{7}{*}{$\begin{array}{l}\text { Docente } \\
\text { Informante } 2 \\
\text { La Pupila }\end{array}$} & disminución de la capacidad visual & Discapacidad \\
\hline & $\begin{array}{l}\text { Puede tener varios orígenes ...s orígenes o diversas etiologías, puede } \\
\text { ser ... de tipo degenerativo, de tipo genético, puede ser de tipo } \\
\text { este... prenatal, perinatal, postnatal }\end{array}$ & $\begin{array}{l}\text { Causas y } \\
\text { clasificación de la } \\
\text { discapacidad }\end{array}$ \\
\hline & $\begin{array}{l}\text { considerar a la persona como ser humano como persona como ser } \\
\text { integral }\end{array}$ & \\
\hline & el docente la persona el personal que labore & Ser integral \\
\hline & ... debe tener la sensibilidad y el conocimiento y & Valores \\
\hline & $\begin{array}{l}\text { Años trabajando.... } \\
\text { desde una visión totalmente clínica hasta una visión más basada en el } \\
\text { episteme de la construcción }\end{array}$ & Formación \\
\hline & $\begin{array}{l}\text { conozco la ley de bioética desde los términos de investigación ... trato } \\
\text { de adaptar las estrategias que empleo por ejemplo usando correos de } \\
\text { voz...e }\end{array}$ & \\
\hline
\end{tabular}


algunos programas que permitan la eh ser facilitadora de cursos ... y me ha tocado hacer las adaptaciones o adecuaciones curriculares

Modelos de atención

..., pero la humanización implica que hay otros tipos de elementos --es respetar al otro como ser humano ver al otro como un igual como un par independientemente de la raza del de la condición -... la discapacidad ... solamente existe en los ojos de quien lo mira, capacidad distinta,... lo que hay que superar aquí en términos de accesibilidad son las barreras actitudinales

Formación

Humanización

Concienciación

\section{Beneficencia}

No maleficencia

Justicia

Barrera

actitudinal

Informante Sub Categoría

Categoría

Representante

todo aquello que afecta la orientación y movilidad

Movilidad

Informante 3

El Iris

Desarrollo pleno dentro de la sociedad.... los que permitan su integración social,

Integración social

Lo primero que yo tengo que tomar en cuenta, ...tengo un ser humano con una discapacidad presente y que debe ser considerada .... Para poder trabajar con él.

\section{Valores}

tiene que ver con la pertinencia que yo puedo tener..., la humanización

tomar en cuenta al ser humano ante todo, una vez que yo tomo en cuenta al ser humano yo puedo determinar cuál es la accesibilidad,

Tenemos que tomar en cuenta la discapacidad de la persona para poder brindar ese espacio para la accesibilidad.

\section{Pertinencia}

Dignificación

\section{Discapacidad}

Estructuración- Martínez (2004), refiere que la estructuración consiste en una red de conceptos que surge de la entrevista. 


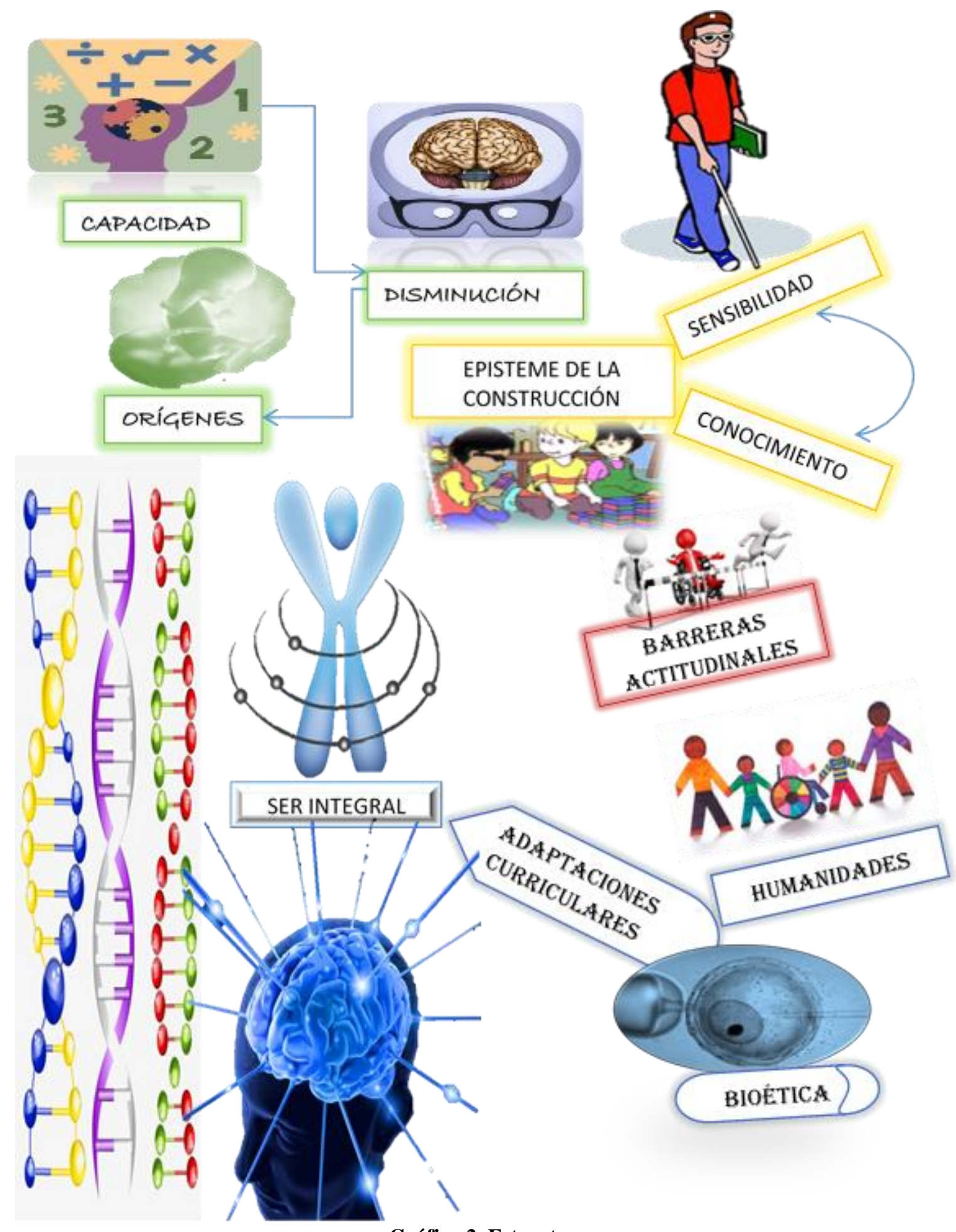

Gráfico 2. Estructura 


\section{Triangulación}

Leal (2009) señala que la triangulación consiste en: "Determinar ciertas intersecciones o coincidencias a partir de diferentes apreciaciones y fuentes informativas o varios puntos de vista del mismo fenómeno". (p.116).

\begin{tabular}{|c|c|c|c|}
\hline Categoría & Entrevista & Documental & Observación \\
\hline $\begin{array}{l}\text { Estimulación } \\
\text { Multisensorial }\end{array}$ & $\begin{array}{l}\text { El tener que } \\
\text { potencializar otro } \\
\text { sentido que te } \\
\text { permitan la } \\
\text { percepción del mundo } \\
\text { como es la audición, el } \\
\text { gusto, el olfato. } \\
\text {.....en cierto modo } \\
\text { vivirla no, }\end{array}$ & $\begin{array}{l}\text { Para Uriarte (2017) La } \\
\text { estimulación multisensorial } \\
\text { es un instrumento utilizado } \\
\text { con el objetivo de mejorar } \\
\text { las condiciones de vida de } \\
\text { las personas con } \\
\text { discapacidad. Para ello se } \\
\text { recurre a medios y } \\
\text { estrategias que trabajan las } \\
\text { capacidades más básicas } \\
\text { del ser humano: las } \\
\text { sensaciones, la percepción } \\
\text { y la integración sensorial. }\end{array}$ & $\begin{array}{l}\text { La discapacidad } \\
\text { visual es una de las } \\
\text { discapacidades que } \\
\text { requiere mayor } \\
\text { compromiso, porque } \\
\text { depende del momento } \\
\text { que se adquiere por lo } \\
\text { que se debe tomar en } \\
\text { cuenta la edad del } \\
\text { estudiante.. }\end{array}$ \\
\hline $\begin{array}{l}\text { Barrera } \\
\text { actitudinales }\end{array}$ & $\begin{array}{l}\text { la discapacidad ... } \\
\text { solamente existe en los } \\
\text { ojos de quien lo mira, } \\
\text {... } \\
\text { capacidad distinta, } \\
\text { lo que hay que } \\
\text { superar aquí en } \\
\text { términos de } \\
\text { accesibilidad son las } \\
\text { barreras actitudinales }\end{array}$ & $\begin{array}{l}\text { Zeskel, M. (2017) refiere } \\
\text { sobre barreras de actitud, } \\
\text { como el conjunto de } \\
\text { dificultades o desafíos } \\
\text { experimentados por una } \\
\text { persona con discapacidad } \\
\text { que resultan de con } \\
\text { comprender, confundir o } \\
\text { ignorar la discapacidad, } \\
\text { mediante la incapacidad } \\
\text { para despedir a la persona o } \\
\text { hacer comparaciones } \\
\text { injustas sobre el } \\
\text { rendimiento laboral de la } \\
\text { persona., }\end{array}$ & $\begin{array}{l}\text { Es importante no } \\
\text { fomentar en el aula } \\
\text { que las personas con } \\
\text { discapacidad no } \\
\text { pueden realizar las } \\
\text { mismas tareas que los } \\
\text { demás y que cuando } \\
\text { cumplen o superan las } \\
\text { expectativas son } \\
\text { tratadas como si sus } \\
\text { acciones fueran } \\
\text { valientes. Se debe } \\
\text { mantener el sentido de } \\
\text { equidad }\end{array}$ \\
\hline Discapacidad & $\begin{array}{l}\text {... tomar en cuenta la } \\
\text { discapacidad de la } \\
\text { persona para poder } \\
\text { brindar ese espacio } \\
\text { para la accesibilidad. }\end{array}$ & $\begin{array}{l}\text { Portos y Merino (2012) } \\
\text { definen la discapacidad } \\
\text { como es una condición que } \\
\text { hace que una persona sea } \\
\text { considerada como } \\
\text { discapacitada. }\end{array}$ & $\begin{array}{l}\text { Se debe resaltar que la } \\
\text { discapacidad es una } \\
\text { condición y no una } \\
\text { enfermedad ni un } \\
\text { impedimento para } \\
\text { realizar la mayoría de } \\
\text { las tareas. }\end{array}$ \\
\hline
\end{tabular}

\section{Discusión de los Resultados}

En relación a la perspectiva que dirigió la indagación del plano cualitativo de los informantes clave investigados que generaron el encuentro con la realidad susceptible de ser interpretada, referida en las secciones precedentes y la cual estuvo entramada con la necesidad de reajustar todas y cada una de las dimensiones de discapacidad, inclusión y equidad desde la familia y la escuela; permitieron resignificar que es de suma importancia el proceso de inclusión en la praxis pedagógica para garantizar el derecho de equidad e igualdad de condiciones y oportunidades que tienen las personas que por diversas etiologías presentan 
discapacidad para recibir una educación de calidad mediante la integración de la familia y la escuela

De igual modo, se evidenció el interés de desarrollar esta interpretación desde dos escenarios diferenciados: uno, orientado a la necesidad de gestionar el cambio a través del conocimiento para el abordaje pedagógico de los niños con discapacidad, y por otra, contribuir con la creación de iguales oportunidades con sus respectivas adecuaciones en las diferentes dimensiones de la accesibilidad, por lo que la investigadora refiere el cuerpo de interpretaciones de los logros obtenidos a través de los objetivos planteados. En este trabajo investigativo, se profundizaron los supuestos teóricos referenciales de la discapacidad, la equidad, la familia y la escuela, por lo que se expuso a través del avance en la comprensión de la discapacidad, precisando que su teorización está interrelacionada e con la integración de estos elementos claves para el bienestar del niño con necesidades educativas especiales.

Es así, como al ser conceptualizada la discapacidad desde un enfoque bio-psico-social, como un proceso multidimensional resultado de la interacción dinámica del funcionamiento, la discapacidad y los factores contextuales, que se brinda una particular importancia a los factores ambientales (sin dejar a un lado lo actitudinal), enfatizando que una parte fundamental de los inconvenientes y dificultades que tienen las Personas con discapacidad para su autonomía, no son las características de su propia condición, sino la interferencia a su independencia al mantener obstáculos y barreras en el entorno social. Por lo que dependiendo de la adecuación del ambiente (o de estas dimensiones), las personas tendrán cada vez menos limitaciones en la actividad y restricciones en la participación social.

Por otra parte, se puso de manifiesto la disposición actitudinal de los docentes involucrados para favorecer el desarrollo de sus propias potencialidades y calidad humana desde la implementación de los valores y puesta en práctica de los principios fundamentales de la inclusión. Igualmente, la investigación destacó, en primer lugar, el carácter histórico de la exclusión social y la igualdad como referente característica de la sociedad que se instituye como un obstáculo psicosocial muy fuerte que debe ser revertido en un proceso que posicione la justicia como precursora de la autonomía personal. Sin embargo, ese modelo cultural de exclusión social está todavía cimentado en la memoria histórica de este país, por lo que la educación ecuatoriana tiene un desafío importante que enfrentar.

Cabe mencionar, que otro aspecto que emergió de la investigación fue la familia considera que su rol es determinante en el éxito escolar, y en la vida misma del niño con discapacidad, toda vez que destaca que un pilar fundamental para la equidad es la comunicación entre la escuela y la familia. De acuerdo con los hallazgos, se destacó la importancia de una visión educativa que trascienda de lo estrictamente educacional y se convierta en una herramienta fundamental para la transformación de vida del niño con discapacidad, puntualizando los alcances y el valor como epicentro para la formación de una nueva sociedad la integración entre la escuela y la familia. El sentido de respeto, equidad, inclusión y la justicia son principios inalienables e individuales para lograr el afianzamiento de una educación centrada en las necesidades y aspiraciones de este colectivo que supere el concepto que se tiene de sí mismo ante la compleja humanidad. 


\section{Bibliografía}

Aguado, A., (1995). La Universidad de Oviedo y los estudiantes con discapacidad. Intervención Psicosocial, 15(1), 49-63.

Bayot, A., Rincón, B. \& Hernández, F. (2002). Orientación y atención a la diversidad. Descripción de programas y acciones en algunos grupos emergentes. Revista Electrónica de Investigación y Evaluación Educativa, 8, 1

Blanco, A. (2009). Procesamiento Fonológico, apoyo a la familia, y el auto concepto académico como predictores de la lectura infantil. Revista Canadiense de Educación.

Blanco, M. (2006). Accessibility of Electronically Mediated Education: Policy Issues. Assistive Technology, 16(2), 85. ( $\mathrm{N}^{\circ}$. de servicio de reproducción de documentos EJ727745).

Burgdorf, R.C. (1980). Universal Design in Higher Education. From principles to practice. Cambridge: Harvad Education Press.

Cabra de Luna, M. A. (2004). Discapacidad y aspectos sociales: la igualdad de oportunidades, la no discriminación y la accesibilidad universal como ejes de una nueva política a favor de las personas con discapacidad y sus familias. Revista del Ministerio de Trabajo y Asuntos Sociales. No. 50. Madrid.

Cabra de Luna, M. A., Bariffi, F. y Palacios, A. (2007). Derechos humanos de las personas con discapacidad: La convención Internacional de la Naciones Unidas. Madrid: Ramón Areces.

Delgado, M. (2009). La Relación Familia-Escuela. El Apoyo de los Padres a la Educación: Clave para el desempeño. Educación. México.

Diccionario de las Ciencias de la Educación (1984). Santillana, S.A. Diagonal.

Hernández, S.; Fernández, C.; y Baptista, L. (2003). Metodología de la Investigación México: Mc Graw Hill Interamericana.

Hurtado, I. y Toro, J. (1998). Paradigmas y Métodos de Investigación en tiempos de cambio. Valencia, Venezuela: Episteme.

Martínez, M. (2001). El paradigma Emergente. México: Trillas.

Martínez, M. (2004). Ciencia y arte en la Metodología Cualitativa. México: Trillas. Naciones Unidas. Normas Uniformes sobre la Equiparación de Oportunidades para las Personas con Discapacidad. $3^{\text {a }}$ Comisión. Tema 109 del Programa. New York. Estados Unidos de América. 1993.

Organización de las Naciones Unidas (1945). Carta de las Naciones Unidas. ONU, San Francisco, Estados Unidos. 
Organización de las Naciones Unidas (1948). Declaración Universal de los Derechos Humanos. Asamblea General de la Naciones Unidas. París: ONU.

Organización de las Naciones Unidas (1975). Declaración de los Derechos de las Personas con Discapacidad. Asamblea General 3447 (XXX). París. ONU.

Organización de las Naciones Unidas (1982). Programa de Acción Mundial para las personas con Discapacidad. ONU.

Organización de las Naciones Unidas para la Ciencia, la Educación y la Cultura (1998b). Declaración Mundial sobre Educación Superior en el Siglo XXI, Visión y Acción. UNESCO.

Organización de las Naciones Unidas para la Ciencia, la Educación y la Cultura (2005b). Estudio Regional sobre Educación Superior en América Latina y el Cari be, I. Seminario Regional sobre la Inclusión de las Personas con Discapacidad en la Educación Superior en América Latina y el Caribe, UNESCO-IESAL

Pisonero, M., A. (2007). La discapacidad social, un modelo para la comprensión de los procesos de exclusión. CIDEC, Zerbitzuan 41, 99-106.

Porto y Merino (2012). Definición de discapacidad. Consulta en línea https://definicion.de/discapacidad/

Romero (2015) Inclusión, Ética, Escuela y Familia. Universidad Complutense. Madrid.

Taylor, S.J. Bogdan, R. (1992). Introducción a los métodos cualitativos en investigación. La búsqueda de los significados. Ed.Paidós, España, 1992-Pág-100 -132.

UNESCO. (1994). Declaración de Salamanca. [Consulta en línea] disponible: www.unesco.org/education/pdf/SALAMA_S.PDF-Francia.

Uriarte A., R. (2008). Estimulación Temprana y Desarrollo Infantil. Editado por EDAF. https://www.significados.com/pertinencia/ incorporacionintegracioneinclusion.blogspot.com/

Zeske, M. (2017). Barreras actitudinales. Consulta en línea http://www.ehowenespanol.com/sonbarreras-actitudinales-info_429937/ 